\title{
Papers
}

\section{Smoking and dementia in male British doctors: prospective study}

\author{
Richard Doll, Richard Peto, Jillian Boreham, Isabelle Sutherland
}

\begin{abstract}
Objective To assess the possible association between smoking and dementia.

Design Prospective study.

Setting Cohort of British male doctors followed up since 1951.

Subjects 34439 male British doctors, with 24133 deaths recorded.

Results For all types of dementia combined the relative risk was 0.96 (95\% confidence interval 0.78 to 1.18), based on 473 deaths at a mean age of 81 years. For probable or definite Alzheimer's disease, the relative risk in continuing smokers was 0.99 (0.78 to 1.25), based on 370 deaths at a mean age of 82 years. In aggregate, however, the other prospective studies indicate a direct, although not clearly significant, association between smoking and the onset of dementia in general and of Alzheimer's disease in particular.

Conclusions Contrary to previous suggestions persistent smoking does not substantially reduce the age specific onset rate of Alzheimer's disease or of dementia in general. If anything, it might increase rather than decrease the rate, but any net effect on severe dementia cannot be large in either direction.
\end{abstract}

\section{Introduction}

Among the few diseases claimed to occur more often in non-smokers than smokers ${ }^{12}$ that of greatest potential importance is Alzheimer's disease, which accounts for most of the dementias of later life in Britain. The published epidemiological evidence, although suggestive of an inverse relation with smoking, is not conclusive either about Alzheimer's disease or dementia in general. Much of the evidence derives from small retrospective studies of uncertain reliability, many of which excluded vascular dementia. Prospective studies, in which smoking habits are recorded before the onset of dementia, should be more informative about the overall effects of smoking, particularly if they concern large numbers and prolonged follow up. Only a few such studies have, however, been properly reported (none of which had prolonged follow up). We sought evidence from the cohort of British doctors who have been followed since 1951, with their smoking habits reviewed every six to 12 years. ${ }^{3}$ Many have died from or with some type of dementia over the past two decades.

\section{Subjects and methods \\ The cohort}

The cohort originally comprised 34439 male doctors on the British medical register, resident in the United Kingdom, who had responded to a questionnaire about their smoking habits in 1951. Changes in such habits were sought in 1957, 1966, 1972, 1978, 1990, and 1998, and other personal information was sought in 1978, 1990, and 1998. In 1971, follow up was discontinued for 2459 subjects ( $10.1 \%$ of the survivors) who were living abroad and $218(0.9 \%)$ for other reasons. ${ }^{4}$ Almost all of the remaining survivors have continued to provide information about their smoking habits.

\section{Death with dementia}

Because the subjects are or were registered medical practitioners, almost all of the survivors living in the United Kingdom can be traced, and few deaths are missed. The present analyses concern 24133 deaths occurring up to 31 December 1998. In 483 cases dementia was mentioned on the death certificate. Two cases were excluded because dementia was attributed respectively to head injury and glioma, and eight because death occurred in 1951-61, less than 10 years after smoking habits were first recorded. The main analyses were based on the 473 deaths that occurred in 1962-98. As most cohort members were comparatively young in 1951, $402(85 \%)$ of these deaths were in the last two decades of follow up. The 95 deaths that occurred in 1996-8 were also the subject of a substudy of the correspondence between the medical history and information given on the death certificate.

\section{Smoking as last recorded 10 or more years ago}

Dementia may progress only slowly, but in those who died of or with dementia in 1996-8 it seldom lasted more than 10 years from first being recognised until death. Our analyses therefore concern data as last recorded 10 or more years before death, to avoid any material effect of the disease itself on smoking habits. As questionnaires were sent out only every six to 12 years, the mean time before death that the relevant smoking habits had been recorded was not 10 but 15

\section{Editorial by Brayne \\ Clinical Trial Service Unit and Epidemiological Studies Unit, Radcliffe Infirmary, Oxford OX2 6HE \\ Richard Doll emeritus professor of medicine \\ Richard Peto director Jillian Boreham senior research fellow Isabelle Sutherland research assistant \\ Correspondence to: R Doll}

BMJ 2000;320:1097-102 
years. Our primary comparison is of subjects who were at that time continuing smokers versus a combination of those who were lifelong non-smokers or ex-smokers. We combined lifelong non-smokers and ex-smokers because most of the latter group had stopped smoking several decades ago (when it became clear to British doctors that smoking was a major cause of premature death), so the ex-smokers who died from or with dementia had on average given up smoking 34 years before death. Conversely, as most of the relevant deaths were in recent years, after the period when large scale cessation was occurring, most who were classified as continuing smokers would (but for any effects of illness) have remained so for several more years. Thus our analyses effectively relate dementia to persistent smoking.

\section{Underlying causes or associated conditions}

Information about the underlying and associated causes of death for those who died and were included in the main analyses was sought from death certificates. Of those known to have died between 1962 and 1998, 269 (56.9\%, mean age at death 81.6 years) had dementia given as the underlying cause of death, and 204 others (43.1\%, 80.6 years) had dementia given as an associated condition - that is, mentioned in any other way on the death certificate. In deciding whether dementia was the underlying cause of death we followed the procedure adopted by the Office of Population Censuses and Surveys from 1984 to 1992. During this period, the census and surveys office did not accept certain conditions that were often terminal, such as bronchopneumonia or pulmonary embolism, as the underlying cause of death if they could be considered a sequel of any more specific condition, even if it was referred to only as an associated condition on the certificate. $^{5}$ This procedure was abandoned when other countries failed to follow suit, but it is medically sensible and we have adopted it for the whole period of our study.

\section{Types of dementia}

The two main types of dementia in this population were Alzheimer's disease and cerebral vascular disease, but it is often difficult to distinguish reliably between them without postmortem histopathology-and even then both may coexist and be jointly responsible for symptoms of dementia. Any subdivision of dementia type that is based chiefly on the death certificate is bound to be inaccurate. To assess the correspondence between medical evidence and the death certificate we undertook a substudy of the 95 deaths with dementia that occurred during the last three years of the study. We sought information from the certifying doctors

Table 1 Correspondence between information from 81 death certificates that mentioned dementia in 1996-8 and information from fuller inquiries of responsible doctors

\begin{tabular}{lccccc} 
& \multicolumn{4}{c}{ Diagnosis after review } & \\
\cline { 2 - 6 } Death certificate diagnosis & $\begin{array}{c}\text { Alzheimer's } \\
\text { disease }\end{array}$ & $\begin{array}{c}\text { Probable } \\
\text { Alzheimer's }\end{array}$ & $\begin{array}{c}\text { Vascular } \\
\text { dementia }\end{array}$ & $\begin{array}{c}\text { Lewy body } \\
\text { disease }\end{array}$ & $\begin{array}{c}\text { All } \\
\text { diagnoses }\end{array}$ \\
\hline Alzheimer's disease & 14 & 5 & 2 & 0 & 21 \\
\hline Senile dementia or dementia unqualified & 10 & 18 & 13 & 3 & 44 \\
\hline Vascular dementia & 1 & 0 & 12 & 0 & 13 \\
\hline Lewy body disease & 0 & 0 & 0 & 3 & 3 \\
\hline All diagnoses & 25 & 23 & 27 & 6 & 81 \\
\hline
\end{tabular}

and, if necessary, hospital consultants about the duration of dementia at the time of death and the basis on which the specific type of dementia was diagnosed. Such information was obtained for 81 of the deaths. For these, we used our inquiries to classify the type of dementia from the best available evidence, but for the other deaths with dementia only the diagnoses on death certificates were available. Of the 473 accepted cases of dementia among men who died 10 or more years after their smoking habits had first been recorded, $95(20 \%)$ were described as due to Alzheimer's disease or to presenile dementia. We consider both of these to have been "specified as Alzheimer's disease." A further 275 (58\%) were described as senile dementia or as dementia with no further qualification, both of which we classify as "probable Alzheimer's disease," since most could equally well have been described as Alzheimer's disease. Finally, 97 (21\%) were described as multiinfarct dementia or as dementia with cerebrovascular disease, both of which we classify as "vascular dementia" and six (1\%) as dementia due to Lewy body disease. The number of deaths attributable to Lewy body disease may have been substantially more than the six recorded, but the disease has only recently begun to be referred to on death certificates, and all our six cases were recorded in the three years for which we sought additional information.

Table 1 shows the correspondence between the classification based only on the death certificate and that based on our inquiries for the 81 deaths for which we have additional medical information. We failed to obtain any further information for the remaining 14 deaths that occurred in 1996-8 because either we could not trace the certifying doctor or we received no reply to repeated inquiries. Overall, the correspondence is reasonably good, although our classification probably underestimates vascular dementia; $28 \%(18 / 65)$ of the cases of dementia that, from the death certificate alone, we would have attributed to probable or definite Alzheimer's disease were reclassified, blind to knowledge of smoking habits, as due to vascular or other causes, whereas only $6 \%(1 / 16)$ were reclassified in the opposite direction. Consequently it is not surprising that we attributed $78 \%(370 / 473)$ of all dementias to probable or definite Alzheimer's disease, whereas the two year prospective European study of the incidence of dementia, ${ }^{6}$ which involved detailed clinical examination with standardised criteria ${ }^{7}$ attributed only $67 \%$. If, however, we had restricted our definition of Alzheimer's disease to cases where the death certificate explicitly specified Alzheimer's disease or presenile dementia (only 10\% of those for which we have additional information were reclassified as vascular or Lewy body disease), we would have classed only $20 \%$ of all dementias as Alzheimer's disease, which would have been far too few.

We considered whether to class dementia with parkinsonism as a separate clinical category, as parkinsonism is known to be protected against to some extent by smoking. ${ }^{4}$ We decided not to, however, for although the late stages of parkinsonism may involve some degree of cognitive decline, the dementias that occur with parkinsonism are mostly due to concomitant Alzheimer's disease or vascular disease ${ }^{910}$ and there is no clear evidence that parkinsonism per se causes any 
Table 2 Deaths of or with dementia versus matched controls: relation with smoking status as last recorded at least 10 years earlier

\begin{tabular}{lccc} 
& \multicolumn{2}{c}{ No of cases (controls) } & \multirow{2}{*}{ Relative risk (95\% Cl) } \\
\cline { 2 - 3 } Category of dementia & Continuing smokers & Not continuing & \\
\hline Dementia probably or definitely due to Alzheimer's disease & $147(591)$ & $223(889)$ & $0.99(0.78$ to 1.25$)$ \\
\hline Specified as Alzheimer's disease & $30(136)$ & $65(244)$ & $0.83(0.51$ to 1.33$)$ \\
\hline Probable Alzheimer's disease & $117(455)$ & $158(645)$ & $1.05(0.80$ to 1.37$)$ \\
\hline Other dementia & $43(187)$ & $60(225)$ & $0.86(0.55$ to 1.34$)$ \\
\hline Vascular dementia & $41(180)$ & $56(208)$ & $0.84(0.53$ to 1.33$)$ \\
\hline Lewy body dementia & $2(7)$ & $4(17)$ & $1.22(0.17$ to 8.69$)$ \\
\hline Any dementia & $190(778)$ & $283(1114)$ & $0.96(0.78$ to 1.18$)$ \\
\hline Dementia as underlying cause & $92(392)$ & $177(684)$ & $0.91(0.69$ to 1.20$)$ \\
\hline Dementia as associated condition & $98(386)$ & $106(430)$ & $1.03(0.75$ to 1.41$)$ \\
\hline
\end{tabular}

*Lifelong non-smokers and long term ex-smokers (for whom mean time since they stopped smoking was 34 years).

material increase in the incidence of dementia. An exception might be some of the cases of dementia due to Lewy body disease, which have recently been distinguished from other dementias and which are associated with parkinsonism. This parkinsonism may sometimes, however, be secondary to Lewy body disease. We have therefore ignored any mention of parkinsonism when classifying the type of dementia.

\section{Statistical methods}

To analyse the possible relation between smoking and dementia we compared each case of dementia with four age matched controls. Because the all cause mortality rate is much higher among smokers than non-smokers the prevalence of smoking is substantially higher among those dying at a particular age than among those of that age who do not die until some later year. Hence if smoking were irrelevant to dementia the prevalence of smoking would be substantially higher among those dying at a particular age with dementia as an associated condition (many of whose deaths would have been caused by smoking) than among those dying at that age with dementia as the underlying cause (none of whose deaths would have been caused by smoking). Our case-control comparison was, therefore, done in two parts, the analyses of which were then combined. Firstly, each doctor who was certified as having died with dementia as the underlying cause was randomly matched with four controls with the same year of birth who were alive on the date he had died, yielding a standard mortality analysis. Secondly, each doctor who died of another underlying cause, but whose death certificate mentioned dementia as an associated condition, was matched with four controls (with the same year of birth) who had died in the same year as he had died: this makes due allowance for the extent to which the fatal effects of smoking increase the prevalence of smoking among those who die at a given age in comparison with the survivors at that age. The process of selecting controls began with the last to have died of or with dementia before the end of the study in 1998 and worked backwards, thus avoiding the risk of selecting as controls doctors who subsequently died with dementia while still avoiding any systematic biases between cases and their matched controls. To obtain four controls for each case the birth date matching criteria had to be relaxed (to allow the year of birth to differ by one year) for only $0.8 \%$ of the controls.

The relations between smoking and dementia, or particular types of dementia, involved standard
Mantel-Haenszel analyses of the relevant contingency tables of smoking versus case or control status, unmatched but stratified for type of case (underlying or associated) and for age in 5 year age groups. Virtually identical results would have been obtained either by wholly unstratified analyses or by more finely stratified analyses that retained the full matching so that each stratum contained only one case and four controls (data not shown). The final observed minus expected $(\mathrm{O}-\mathrm{E})$ and its variance $(\mathrm{V})$ were then used to calculate the $\log$ relative risk $\mathrm{b}=(\mathrm{O}-\mathrm{E}) / \mathrm{V}$ and its standard error $1 / \sqrt{ } \mathrm{V}$, from which the relative risk describing the relation between smoking and dementia is $\exp (\mathrm{b})$ with 95\% confidence limits exp(b SE 1.96).

\section{Results}

The distinction between different types of dementia is uncertain and there was no significant relation between any dementia and smoking (relative risk 0.96 , $95 \%$ confidence interval 0.78 to 1.18 ; mean age at death 81 years: table 2). Only $2 \%$ of the deaths with dementia occurred before age 65 , which is too few for separate analysis to be informative. These overall results are also divided according to whether dementia was described as the underlying cause of death or as an associated condition. As expected the proportion of current smokers was substantially higher $(48 \%$; 98/204) when dementia was an associated condition in those who had died for some other reason than when dementia was the underlying cause (34\%; 92/269), because at any given age the mortality from causes other than dementia is much higher in smokers than in non-smokers and long term ex-smokers. ${ }^{4}$ This, however, applied equally to cases and their matched controls, and in our unbiased comparisons with appropriate controls the relative risks for dementia as underlying cause and for dementia as associated condition were both close to, and not significantly different from, unity.

Dementia involving Alzheimer's disease was likewise neither directly nor inversely related to continued smoking, the proportion of continuing smokers being $40 \%(147 / 370)$ in the doctors who had developed it and 40\% (591/1480) in their matched controls (relative risk $0.99,0.78$ to 1.25 ; mean age at death 82 years: table 2).

No significant association was found between continued smoking and the aggregate of all other types of dementia (relative risk $0.86,0.55$ to 1.34 ; mean age at death 80 years: table 2 ). Most of these cases concerned 
Table 3 Relation with lifelong smoking status in male doctors who died of or with dementia versus matched controls

\begin{tabular}{|c|c|c|c|c|c|c|c|}
\hline \multirow[b]{2}{*}{ Type of dementia } & \multicolumn{3}{|c|}{ No of cases (controls) } & \multirow[b]{2}{*}{ Heterogeneity } & \multicolumn{3}{|c|}{ Risk ratio $(95 \% \mathrm{CI})$} \\
\hline & $\begin{array}{l}\text { Continuing } \\
\text { smokers }\end{array}$ & $\begin{array}{l}\text { Long term } \\
\text { ex-smokers* }\end{array}$ & $\begin{array}{l}\text { Never smoked } \\
\text { regularly }\end{array}$ & & $\begin{array}{l}\text { Continuing } v \\
\text { ex-smokers* }\end{array}$ & $\begin{array}{c}\text { Continuing } v \text { never } \\
\text { smokers }\end{array}$ & $\begin{array}{l}\text { Ex }^{\star} v \text { never } \\
\text { smokers }\end{array}$ \\
\hline $\begin{array}{l}\text { Probably or definitely due } \\
\text { to Alzheimer's disease }\end{array}$ & 147 (591) & $156(665)$ & $67(224)$ & $\chi^{2}=2.2, P=0.3$ & 1.07 (0.83 to 1.38$)$ & 0.83 (0.60 to 1.16$)$ & 0.78 (0.56 to 1.10$)$ \\
\hline Vascular or Lewy body & $43(187)$ & $44(162)$ & $16(63)$ & $\chi^{2}=0.5, P=0.8$ & 0.83 (0.51 to 1.34$)$ & 0.94 (0.49 to 1.82$)$ & 1.07 (0.57 to 2.02$)$ \\
\hline Any & $190(778)$ & $200(827)$ & $83(287)$ & $\chi^{2}=1.6, P=0.4$ & 1.01 (0.81 to 1.27$)$ & $0.85(0.63$ to 1.14$)$ & $0.84(0.63$ to 1.13$)$ \\
\hline
\end{tabular}

*Stopped smoking on average 34 years.

vascular dementia, which like vascular mortality in this population ${ }^{4}$ might have been expected to be directly related to smoking. The remainder (all six of which occurred in 1996-8) were classified as Lewy body dementia, but there were too few such cases to provide much useful information.

Table 3 shows the results for dementia involving Alzheimer's disease, for other dementia, and for any dementia when continuing smokers are compared separately with long term ex-smokers and with lifelong non-smokers. For no type of dementia is there any significant heterogeneity between these three categories of smoker. For dementia attributable to Alzheimer's disease, the risk seems to be slightly greater in continuing smokers than in ex-smokers and slightly smaller in continuing smokers than in lifelong non-smokers. Neither of these differences is, however, statistically significant, and the overall relative risk when continuing smokers are compared with all others is almost exactly unity $(0.99,0.78$ to 1.25$)$, indicating no adverse or protective effect whatever (table 2). As the relative risk for probable or definite Alzheimer's disease when continuing smokers are compared with lifelong non-smokers $(0.83,0.60$ to 1.16$)$ is similar to that when ex-smokers are compared with lifelong non-smokers $(0.78,0.56$ to 1.10 ), it is likely that both have been similarly distorted by the effects of the play of chance on the results for the small number of lifelong non-smokers, who constituted only a quarter of the total number of non-smokers or ex-smokers.

\section{Discussion}

Our data do not suggest that prolonged smoking either increases or decreases the likelihood that men of a given age will develop dementia or that they will develop dementia involving Alzheimer's disease.

\section{Special features of the present study}

The main strength of our study is its unusually long and complete follow up. This, together with persistently high response rates to the repeated questionnaires, ensures that the smoking habits were recorded reliably some years before they could be materially distorted by the onset of dementia. Hence, the subjects can be reliably classified according to their smoking habits about 15 years before death, and it is reasonable to assume that in most cases these habits would have persisted for several more years unless affected by disease.

Another strength is that the dementia analysed must have been definite and severe to have justified mention on the death certificate. This means, however, that mild dementia must have been underreported, particularly during the first few decades of the study. During the last two decades of the study 236 deaths were attributed to dementia (which must in each case have been severe irrespective of whether it actually caused death). But of the 10092 other deaths in these two decades only 169 had dementia given as an associated condition, whereas at the age specific prevalence rates reported for European men in 1980-90 we would have expected 1115 to have been classifiable on interview as having some degree of dementia (by DSM-III criteria). ${ }^{11}$ Hence we probably recorded only about $30 \%(236+169 / 236+1115)$ of the cases of dementia that would have been recorded if each man had been interviewed before death (or somewhat more than $30 \%$ if higher education is associated with lower rates of dementia on interview). This shortfall is not surprising as dementia that is only mild is unlikely to have been mentioned on the death certificate, and it will cause no bias as there is no reason to suppose that the decision to mention dementia would have been materially influenced by the individual's previous smoking habits.

Misclassification of the type of dementia will certainly also have occurred, not only because many of the cases of dementia that we classed as "probable" Alzheimer's disease will have had a vascular component, but also because the specific diagnosis of Alzheimer's disease cannot be determined with certainty without postmortem examination, and this was seldom sought. Even substantial misclassification does not, however, invalidate our main conclusions about dementia as a whole.

Limitations of the retrospective studies

At least 30 reports of epidemiological studies of smoking and Alzheimer's disease or probable Alzheimer's disease have now been published, but few are reliable. Most were case-control studies in which information had to be obtained from surrogates, especially where the dementia was severe. Although there are circumstances where appropriate retrospective studies can yield useful results, there are two particular ways in which retrospective studies of smoking and dementia could indicate a misleadingly protective effect. Firstly, the disease itself will, as it progresses, eventually change smoking habits, so inquiries have to be made about habits several years earlier. Even if surrogate informants are used, a brief period of smoking many years ago may be more likely to be overlooked in a person with dementia than in a control with no dementia, leading to an apparently protective effect among ex-smokers, particularly those who smoked only briefly. Secondly, if the controls are chosen from patients who are attending hospital for other reasons then smokers may be overrepresented among them, since smokers may be substantially more likely to be attending hospital than would be non-smokers of a similar age. 
Table 4 Main results of four prospective studies of smoking and dementia

\begin{tabular}{|c|c|c|c|c|c|c|}
\hline \multirow[b]{2}{*}{ Study } & \multirow{2}{*}{$\begin{array}{c}\text { Contrast in smoking } \\
\text { habits }\end{array}$} & \multirow{2}{*}{$\begin{array}{c}\text { Follow up } \\
\text { duration } \\
\text { (years) }\end{array}$} & \multicolumn{2}{|c|}{ Alzheimer's disease } & \multicolumn{2}{|c|}{ Any dementia } \\
\hline & & & No of cases & Risk ratio $(95 \% \mathrm{Cl})$ & No of cases & Risk ratio $(95 \% \mathrm{Cl})$ \\
\hline \multicolumn{7}{|c|}{ Short term studies of incident disease on reinterview } \\
\hline Wang et al ${ }^{18}$ (both sexes, aged $\geqslant 75$ ) & Ever $^{\star} v$ never & 3 & 34 & $1.1(0.5$ to 2.4$)$ & 46 & $1.4(0.8$ to 2.7$)$ \\
\hline Hebert et $\mathrm{al}^{17}$ (both sexes, aged $\geqslant 65$ ) & Ever $v$ never & 3 & 76 & $0.7(0.3$ to 1.4$)$ & - & - \\
\hline Launer et al ${ }^{6}$ (both sexes, aged $\geqslant 65$ ) & Current $v$ never & 2 & 277 & 1.74 (1.21 to 2.50$)$ & 400 & 1.39 (1.03 to 1.89$)$ \\
\hline \multicolumn{7}{|c|}{ Long term study of dementia on death certificate } \\
\hline Doll et al (male UK doctors) & Current $v$ not† & 47 & 370 & 0.99 (0.78 to 1.25$)$ & 473 & $0.96(0.78$ to 1.18$)$ \\
\hline
\end{tabular}

${ }^{*}$ Excludes those who had smoked less than five cigarettes per day and stopped several decades ago.

†Smoking status as last determined at least 10 years (mean 15 years) before death: our current smokers were at that time still continuing to smoke. Our ex-smokers stopped a mean of 34 years before death, so comparison group includes them: inclusion of ex-smokers in the Launer et al comparison group would change their risk ratios into 1.64 (1.16 to 2.31) for Alzheimer's disease and 1.38 (1.03 to 1.84) for any dementia.

\section{Reports of prospective studies}

Prospective studies are less likely to be affected by such biases, and we have identified eight. The report of one, however, was biased in favour of indicating a direct association of dementia with smoking ${ }^{12}$ because it analysed deaths in which dementia was mentioned as an associated cause in the same category as deaths in which dementia was referred to as the underlying cause. The reports of four others were biased in favour of an inverse association with smoking as they presented relative risks for men and women combined without adjusting for sex. ${ }^{13-16}$ (In old age, dementia is more common among women than men $^{11}$; analyses that do not allow for this will indicate artefactually high risks in non-smokers.) In addition, one report had substantial numerical inconsistencies. ${ }^{16}$

Only three of these eight prospective studies were reported with appropriate adjustment for age, sex, and education. ${ }^{6}{ }^{1718}$ All three included both men and women and assessed the incidence of dementia by interviewing survivors, but involved only short term follow up (so those assessed as having dementia absent at entry and present only 2-3 years later may need to be followed for several more years to discover who

\section{What is already known on this topic}

Previous epidemiological evidence that smoking might protect against Alzheimer's disease chiefly concerned small retrospective studies of uncertain reliability

Short term prospective studies that assessed the incidence of dementia at reinterview suggest, in aggregate, a non-significant adverse effect of smoking

\section{What this study adds}

No significant difference was found between continuing smokers and long term non-smokers, either for dementia as a whole or for dementia attributed to Alzheimer's disease

Smoking could slightly increase rather than decrease the age specific onset rate of dementia, but any net effect on severe dementia cannot be large in either direction

The protective effects previously reported in some small retrospective studies were largely or wholly artefactual develops gross dementia). Of these three incidence studies, two were small: 1649 older adults in east Boston who scored well in a memory test were reinterviewed three years later, ${ }^{17}$ as were 343 in Stockholm who were initially classified as not cognitively impaired. ${ }^{18}$ The third was larger ${ }^{6}$ (combining the results of four substudies from Denmark, France, the Netherlands, and the United Kingdom, and subsuming the previously published findings ${ }^{19}$ ): 12934 adults without overt dementia were reinterviewed after only two years to assess any newly apparent cases.

Table 4 summarises these short term prospective studies of incident disease on reinterview along with our own study. The largest of the short term studies ${ }^{6}$ suggested an increased risk of Alzheimer's disease in smokers whereas the two smaller ones did not. But the apparent heterogeneity between these three results could well be largely due to the play of chance, and overall these three studies indicate a relative risk that is greater than unity, although not conclusively so. In contrast, the present long term study of dementia on death certificates (which would usually indicate severe disease) suggests little or no difference when continuing smokers are compared with lifelong non-smokers plus ex-smokers. This is the most relevant comparison in our study, as on average our ex-smokers had stopped some 34 years before death. Although the distinction between Alzheimer's disease and other forms of dementia is uncertain, our overall finding would have been much the same if all types of dementia had been combined as there is no significant association of continued smoking either with probable or definite Alzheimer's disease or with the aggregate of all dementia.

\section{Conclusions}

Although corrected analyses of the other small prospective studies might be of some interest, those studies would still be limited by their size (and in some cases by the crudeness of the smoking histories they recorded), and it is chiefly from longer follow up of large prospective studies that more reliable results are likely to emerge. Taken together, the four adequate prospective studies indicate a relative risk of about unity or slightly greater than unity (although of these studies two are small and only the present involves long term follow up and comparatively large numbers with dementia). We conclude that the inverse relation between Alzheimer's disease and smoking reported in some small retrospective studies was largely or wholly artefactual and that persistent smoking does not reduce the age specific onset rate of the disease or of 
dementia in general to any substantial extent. If anything, persistent smoking may increase rather than decrease the onset rate of dementia, but any net effect on severe dementia cannot be large in either direction.

We thank the British doctors some of whom have continued to collaborate in this prospective study of their health for almost half a century, Robert Clarke, Rory Collins, and Christina Davies for their comments, and Cathy Harwood and Gale Mead for preparing the manuscript.

Contributors: RD planned the study, IS has for many years conducted it, and RD, RP, and JB planned and conducted the present analyses. RD and RP prepared the report; they will act as guarantors for the paper.

Funding: The Medical Research Council has supported the study since 1951 and continues to do so through direct support of the Clinical Trial Service Unit and Epidemiological Studies Unit, helped by the Imperial Cancer Research Fund and British Heart Foundation.

Competing interests: None declared.

1 Baron JA. The beneficial effects of nicotine and cigarette smoking: the real, the possible, and the spurious. Brit Med Bull 1996;52:58-73.

2 Lee PN. Smoking and Alzheimer's disease. Neuroepidemiol 1994;13:13144 .

3 Doll R, Hill AB. Lung cancer and other causes of death in relation to smoking. A second report on the mortality of British doctors. BMJ 1956;2:1071-6.

4 Doll R, Peto R, Wheatley K, Gray R, Sutherland I. Mortality in relation to smoking: 40 years' observations on male British doctors. BMJ 1994:309:901-11.

5 Office of Population Censuses and Surveys. 1993 Mortality statistics:cause, England and Wales. London: HMSO, 1995:xi-v.

6 Launer LJ, Andersen K, Dewey ME, Letenneur L, Ott A, Amaducci LA, et al and the EURODERM Incidence Research Group and Work Groups. Rates and risk factors for dementia and Alzheimer's disease: results from EURODEM pooled analyses. Neurology 1999;52:78-84.
7 McKahnn G, Drachman D, Folstein M, Katzman R, Price D, Stadlan EM Clinical diagnosis of Alzheimer's disease: report of the NINCDS-ADRDA Work Group under the auspices of the Department of Health and Human Services Task Force on Alzheimer's disease. Neurology 1984:34:939-44.

8 Graves AB, Mortimer JA. Does smoking reduce the risk of Parkinson's and Alzheimer's diseases? J Smoking-related Dis 1994;5(suppl 1):79-90.

9 Braak H, Braak D, Yilmazer D, De Vos RAL, Jansen ENH, Bohl J. Pattern of brain destruction in Parkinson's and Alzheimer's diseases. J Neurol Transm 1996;103:455-90.

10 Jellinger KA. Morphological substrates of dementia in Parkinsonism. A critical update. J Neurol Transm 1997;51(suppl 1):57-82.

11 Hofman A, Rocca WA, Brayne C, Breteler MMB, Clarke M, Cooper B, et al for the EURODERM Prevalence Research Group. The prevalence of dementia in Europe: a collaborative study of 1980-90 findings. Int J Epidemiol 1991;20:736-47

12 Hirayama T. Large cohort study on the relation between cigarette smoking and senile dementia without cerebrovascular lesions. Tobacco Control 1992;1:176-9.

13 Yoshitake T, Kiohara Y, Kato I, Ohmura T, Iwamoto H, Nakayama K, et al. Incidence and risk factors of vascular dementia and Alzheimer's disease in a defined elderly Japanese population. Neurology 1995;45:1161-8.

14 Katzman R, Aronson M, Fuld P, Kawas C, Brown T, Morgenstern H, et al Development of dementing illness in an 80-year-old volunteer cohort. Ann Neurol 1989;25:317-27.

15 Prince M, Cullen M, Mann A. Risk factors for Alzheimer's disease and dementia: a case-control study based on the MRC hypertension trial. Neurology 1994:44:97-104.

16 Merchant C, Tang M-X, Albert S, Manly J, Stern Y, Mayeux L. The influence of smoking on the risk of Alzheimer's disease. Neurology 1999;52:1408-12.

17 Hebert LE, Scherr PA, Beckett LA, Funkenstein HH, Albert MS, Chown MJ, et al. Relation of smoking and alcohol consumption to incident Alzheimer's disease. Am J Epidemiol 1992;135:347-55.

18 Wang H-X, Fratiolioni L, Frisoni GB, Vitanen M, Winblad B. Smoking and the occurrence of Alzheimer's disease: cross-sectional and longitudinal data in a population based study. Am J Epidemiol 1999;149:640-4.

19 Ott A, Slooter AJC, Hofman A, Van Harskamp F, Witteman JCM, Van Broeckhoven C, et al. Smoking and risk of dementia and Alzheimer's disease in a population-based cohort study. Lancet 1998;351:1840-3.

(2 January 2000)

\title{
Educational differences in smoking: international comparison
}

\author{
A E J M Cavelaars, A E Kunst, J J M Geurts, R Crialesi, L Grötvedt, U Helmert, E Lahelma, \\ O Lundberg, J Matheson, A Mielck, N Kr Rasmussen, E Regidor, M do Rosário-Giraldes, Th Spuhler, \\ J P Mackenbach
}

Department of

Public Health,

Erasmus University,

PO Box 1738,

$3000 \mathrm{DR}$

Rotterdam,

Netherlands

A E J M Cavelaars

research associate

A E Kunst

senior researcher

J P Mackenbach

professor

Statistics

Netherlands,

PO Box 4481,

6401 CZ Heerlen,

Netherlands

J J M Geurts

research associate

National Institute of Statistics, Servizio

Studi Metodologica,

00198 Rome, Italy

R Crialesi

senior researcher

continued over

BMJ 2000;320:1102-7

\begin{abstract}
Objective To investigate international variations in smoking associated with educational level.

Design International comparison of national health, or similar, surveys.

Subjects Men and women aged 20 to 44 years and 45 to 74 years.

Setting 12 European countries, around 1990.

Main outcome measures Relative differences (odds ratios) and absolute differences in the prevalence of ever smoking and current smoking for men and women in each age group by educational level. Results In the 45 to 74 year age group, higher rates of current and ever smoking among lower educated subjects were found in some countries only. Among women this was found in Great Britain, Norway, and Sweden, whereas an opposite pattern, with higher educated women smoking more, was found in southern Europe. Among men a similar north-south pattern was found but it was less noticeable than among women. In the 20 to 44 year age group, educational differences in smoking were generally
\end{abstract}

greater than in the older age group, and smoking rates were higher among lower educated people in most countries. Among younger women, a similar north-south pattern was found as among older women. Among younger men, large educational differences in smoking were found for northern European as well as for southern European countries, except for Portugal.

Conclusions These international variations in social gradients in smoking, which are likely to be related to differences between countries in their stage of the smoking epidemic, may have contributed to the socioeconomic differences in mortality from ischaemic heart disease being greater in northern European countries. The observed age patterns suggest that socioeconomic differences in diseases related to smoking will increase in the coming decades in many European countries.

\section{Introduction}

Socioeconomic inequalities in health have been found in all countries where data are available, and there is an 